The most interesting finding concerning the questions to patients was as follows; to the question how they obtained the fear to this injury, the answers of them were "from doctors" in more than $30 \%$ of cases.

We reported in this paper, because we could obtain the excellent results by treating the patients based upon our criterea as shown in Table 1 and 2 .

\title{
178. The Roentgen Diagnosis of the Whiplash Injury
}

\author{
Hajime Handa, Eiichi Tani, Shinsuke Tominaga, Tomio Ohta, Jōji Handa, \\ Minoru Aoyagi, Kōzo Yoshida, Takuro TaKase, Haruhiko Kikuchi, \\ Bin SHIMIzU and Masaru TAKaHASHI \\ Department of Neurosurgery, Kyoto University Medical School
}

As a risk of modern transportation, whiplash injuries of the neck are occurring with increasing frequency. The purpose of the present study is to establish some roentgenographic criteria on which a diagnosis of whiplash injury can be made.

One hundred and seventy patients who had sustained injuries to the neck within past 2 years were examined clinically and roentgenographically. The patients were divided into 2 groups, a younger (below 40 years of age) and an older group (over 41 years of age), and further subdivided into early cases and late cases according to a period elapsed after the injury (Table 1). Clinically, all these patients had, at least, any 2 out of 5 main symptoms peculiar to whiplash injury as shown in Table 2. The roentgenographic views of the cervical spine employed in the present study were the followings: 1) an A-P view, 2) an open mouth view, 3) a lateral view in neutral position, 4) the same, made in maximum flexion, 5) the same, in maximum extension, 6) a right, and 7) a left posterior oblique view.

Percentages in occurrence of abnormal findings in each group are shown

Table 1.

\begin{tabular}{c|l}
\hline Type & \multicolumn{1}{|c}{ Sign and Symptom } \\
\hline I & Pain in the head and/or neck \\
\hline II & Radiculopathy \\
\hline III & Vertebro-basilar insufficiency \\
\hline IV & Autonomic disturbance \\
\hline V & Myelopathy \\
\hline
\end{tabular}


in Tables 3 and 4 . The most frequent findings encountered were an instability of the spine on maximum flexion in early cases of younger group; a spur formation, an instability and a narrowing of the intervertebral foramina in late cases of the same group; and an encroachment of von Luschka joint, a spur formation and an angulation in both early and late cases of the older group, respectively. These findings were considered to be indispensable in diagnosing as whiplash injuries. In other words, diagnosis of whiplash injury should not be made on patients without showing either one of the above mentioned findings.

In order to obtain more sufficient basis for a diagnosis of whiplash injury, however, it should also be elucidate to what degree similar findings may be present in a normal group of persons. For this purpose, 40 persons (20 young and 20

Table 2.

\begin{tabular}{l|c|c|c|c|c|c}
\hline \multirow{2}{*}{} & \multicolumn{4}{|c|}{ whiplash } & \multicolumn{2}{|c}{ normal } \\
\cline { 2 - 7 } & \multicolumn{2}{|c|}{ younger } & \multicolumn{2}{|c}{ older } & younger & older \\
\cline { 2 - 7 } & early & late & early & late & \\
\hline Age & $21-40$ & $24-40$ & $41-61$ & $48-60$ & $21-40$ & $41-21$ \\
Mean & 28.8 & 30.4 & 52.5 & 54.9 & 32.6 & 54.4 \\
\hline Period after injury & $-6 \mathrm{M}$. & $6-24 \mathrm{M}$. & $-6 \mathrm{M}$. & $6-24 \mathrm{M}$. & & \\
Mean & $1.5 \mathrm{M}$. & $14.2 \mathrm{M}$. & $1.8 \mathrm{M}$. & $10.2 \mathrm{M}$. & & \\
\hline No. persons & 100 & 50 & 10 & 10 & 20 & 20 \\
S; 우 & $86 ; 14$ & $37 ; 13$ & $9 ; 1$ & $10 ; 0$ & $12 ; 8$ & $12 ; 8$ \\
\hline
\end{tabular}

Table 3.

$(\%)$

\begin{tabular}{|c|c|c|c|c|c|c|}
\hline & \multicolumn{4}{|c|}{ whiplash } & \multicolumn{2}{|c|}{ normal } \\
\hline & \multicolumn{2}{|c|}{ younger } & \multicolumn{2}{|c|}{ older } & \multirow{2}{*}{ younger } & \multirow{2}{*}{ older } \\
\hline & early & late & younger & late & & \\
\hline $\begin{array}{l}\text { A-P view } \\
\text { Scoliosis }\end{array}$ & 61.0 & 22.0 & 40.0 & 20.0 & 25.0 & 10.0 \\
\hline Increase in inter-pedicular distance & 0 & 0 & 10.0 & 0 & 0 & 5.0 \\
\hline Encroachment of von Luschka joint & 31.0 & 84.0 & 100.0 & 100.0 & 15.0 & 40.0 \\
\hline $\begin{array}{l}\text { A-P view with open-mouth } \\
\text { abnormal relation-ship of } \mathrm{O}-\mathrm{L}^{*}\end{array}$ & 21.0 & 10.0 & 30.0 & 20.0 & 10.0 & 10.0 \\
\hline $\begin{array}{l}\text { Oblique view } \\
\text { Encroachment of intervertecral } \\
\text { foramina }\end{array}$ & 44.0 & 92.0 & 80.0 & 100.0 & 45.0 & 45.0 \\
\hline
\end{tabular}

$\mathrm{O}-\mathrm{L}^{*}$; odontoid process to atlas lateral massess 
Table 4.

(\%)

\begin{tabular}{|c|c|c|c|c|c|c|}
\hline \multirow{3}{*}{ lateral projection } & \multicolumn{4}{|c|}{ whiplash } & \multicolumn{2}{|c|}{ normal } \\
\hline & \multicolumn{2}{|c|}{ younger } & \multicolumn{2}{|c|}{ older } & \multirow{2}{*}{ younger } & \multirow{2}{*}{ older } \\
\hline & early & late & early & late & & \\
\hline $\begin{array}{l}\text { neutral view } \\
\text { straightening }\end{array}$ & 30.0 & 20.0 & 90.0 & 90.0 & 10.0 & 30.0 \\
\hline angulation & 31.0 & 86.0 & 90.0 & 100.0 & 15.0 & 30.0 \\
\hline loss of lordosis & 33.0 & 80.0 & 90.0 & 90.0 & 10.0 & 30.0 \\
\hline spur formation & 69.0 & 98.0 & 100.0 & 100.0 & 50.0 & 80.0 \\
\hline narrowing of inter-vertebral space & 11.0 & 18.0 & 40.0 & 50.0 & 0 & 15.0 \\
\hline $\begin{array}{l}\text { hyperextension view } \\
\text { range of movement* }\end{array}$ & 45.0 & 38.6 & 21.1 & 15.3 & 66.2 & 50.3 \\
\hline instability & 55.0 & 68.0 & 60.0 & 40.0 & 40.0 & 10.0 \\
\hline $\begin{array}{l}\text { hyperflexion view } \\
\text { range of movement* }\end{array}$ & 19.5 & 11.0 & 10.0 & 8.6 & 34.5 & 25.4 \\
\hline instability & 92.0 & 96.0 & 80.0 & 40.0 & 85.0 & 25.0 \\
\hline
\end{tabular}

* ; degree

old persons) who had never be subjected to whiplash injury were also examined radiographically as a control group, and percentages occurrence of similar radiological findings compared with those of whiplash injuries. The following observations were found to be significantly higher in frequency in the injured group than those in the control group; 1) a narrowing of intervertebral foramina in early cases of the younger group, 2) an angulation, an encroachment of von Luschka joint, a loss of lordosis and a narrowing of intervertebral space in late cases of the same group, 3) a scoliosis and an instability on hyperextension in early cases of the older group, and 4) an instability on hyperextension in late cases of the older group. Among these findings, a narrowing of the intervertebral space and a loss of lordosis in the younger group are considered to be the most sufficient basis for making diagnosis of the whiplash injury.

In addition to the study so far mentioned, a further precise measurement on roentgenograph gave the following results.

1) If the right and left difference between odontoid process and lateral masses of the atlas exceeds $3 \mathrm{~mm}$. in the younger and $2 \mathrm{~mm}$. in the older groups, the difference may be considered of diagnostic significance. 2) Positively "limited extension" is referred to the cases whose angle is below 60 degrees in younger, and below 40 degrees in older groups. Positively "limited flexion" is also referred to the cases whose angle is below 20 degrees in the younger, and below 15 degrees 
in the older groups. From these considerations, positively "limited extension" and/or "limited flexion" in the older group give one of the most important factors in diagnosing whiplash injury.

\title{
Summary
}

1) In the younger group, a narrowing of the intervertebral space and a severe limitation of the extension in the early stage, and a loss of lordsis and a marked difference in the distance of odontoid-atlas lateral masses on both sides in the late stage have the important diagnostic significance.

2) In older group, regardless to the different stage, the similar important diagnostic significance are a marked limitation of extension and/or flexion, and the prominent difference in the distance of odontoid-atlas lateral masses on both sides.

3) The relative diagnostic significance is expressed in younger group as a loss of lordosis and a markedly limited flexion in the early stage, an encroachment of von Luschka joint, a markedly limited extension and/or flexion, and an angulation in the late stage.

4) The following findings which can not be significant but essential to diagnose the whiplash injury are summarized as follows: a) In the younger group, an instability of the cervical spine in the early stage, a spur formation, an instability of the cervical spine and an encroachment of the intervertebral foramina. b) In the older group an encroachment of von Luschka joint, a spur formation and an angulation.

\section{Irregular Alignment of the Posterior Margin of Cervical Vertebral Bodies in Cases of the Craniocervical Injury}

\author{
Masahisa Matsumoto, Noriko Miura, Tomio Tsuchida and Yosiaki Mayanagi \\ Department of Neurological Surgery, Central Hospital of Japanese National Rialways \\ Hiroaki SEKINo \\ Department of Neurosurgery, University of Tokyo
}

Irregular alignment of the posterior margin of cervical vertebral bodies at the time of the first examination was observed in 205 adult cases of the craniocervical injury who were treated in our clinic recently.

All cases were tentatively classified into three groups.

Group I: so calld whiplash injury-48 cases. 